\title{
Monografías enterRadas: el PROYECTO MAN in NATURE en Los Altos de Chiapas (1956-1959)
}

\author{
Buried Monographs: The Man in Nature Project \\ in The Highland Chiapas (1956-1959)
}

\author{
Óscar Javier Barrera Aguilera* \\ DOI: https://doi.org/10.31644/ED.V8.N1.2021.A08
}

Resumen: El propósito de este artículo es analizar los resultados que arrojó la primera etapa del proyecto Chicago (1956-1959). Nos concentramos en examinar los trabajos que se dirigieron a producir visiones monográficas o estudiar aspectos específicos de los pueblos tzeltales y tzotziles. En primer lugar, nos ocupamos de la estructura y la cantidad de escritos que reunió el reporte. En segundo lugar, pasamos al análisis de los productos. La intención es describir los documentos producidos e identificar sus principales aportes y aspectos discutibles, así como también mostrar los elementos que llevan a cuestionar las etiquetas "funcionalistas" o "culturalistas" con las que han sido caracterizados estos trabajos, las cuales, más que aclarar, han contribuido a oscurecer su riqueza informativa.

Palabras clave: cambio cultural, historia de la antropología, ladinización, proyecto Man in Nature, pueblos tzeltales y tzotziles.

Abstract: The purpose of this article is to analyze the results of the first stage of the Chicago project (1956-1959). We concentrate on examining the works that were directed to produce monographic visions or to study specific aspects of the Tzeltal and Tzotzil peoples. First of all, we deal with the structure and quantity of documents gathered in the report. Second, we move on to the analysis of the products. The intention is to describe the documents produced and to identify their main contributions and arguable aspects, as well as to show the elements that lead to questioning the "functionalist" or "culturalist" labels with which these works have been characterized, which, more than clarifying, have contributed to obscure their informative wealth.

Keywords: cultural change, history of anthropology, ladinization, Man in Nature project, tzeltal and tzotzil peoples.

\footnotetext{
* Dr. en Historia, becario posdoctoral del Consejo Nacional de Ciencia y Tecnología en el Centro de Estudios Mayas de la Universidad Nacional Autónoma de México, México. ORCiD: https://orcid.org/0000-0002-7704-9596. Correo-e: ojbarreraa@gmail.com.
}

Fecha de recepción: 3/04/2020. Fecha de aceptación: 22/09/2020. Fecha de publicación: 30/01/2021.

\section{(cc) BY-NC-ND}

EntreDiversidades. Revista de Ciencias Sociales y Humanidades, vol. 8, núm. 1 (16), enero-junio 2021. Páginas: 186 - 211 ISSN-e: 2007-7610. https://doi.org/10.31644/ED.V8.N1.2021.A08 


\section{Introducción ${ }^{1}$}

Andrés Medina ha caracterizado el periodo de 1940 a 1970 como uno de gran intercambio entre las comunidades antropológicas de México y Estados Unidos. Sin embargo, recalca que aún es poco lo que sabemos en términos de préstamos conceptuales y metodológicos, así como de conformación de redes académicas. Esto aplica al proyecto Man in Nature, una iniciativa del Departamento de Antropología de la Universidad de Chicago, que entre los años de 1956 a 1962 contó con la participación de estudiantes y especialistas provenientes de Estados Unidos, México y otros países de Europa y América Latina (Medina, 2015).

Luego de la Segunda Guerra Mundial, los Estados Unidos reformularon su agenda de investigación, dentro de la cual las universidades cobraron un papel cada vez más preponderante. En términos de enfoque y escala adquirió reconocimiento el estudio de "áreas culturales", entendidas como extensas unidades analíticas con características compartidas. Hubo algunos ejemplos previos de colaboración académica entre México y Estados Unidos que allanaron el camino al proyecto Man in Nature. Un antecedente significativo fue el que coordinó el antropólogo Robert Redfield, también desde la Universidad de Chicago y con financiación de la Carnegie Institution, a partir de la década de 1930. Esta iniciativa, que en un principio se interesó por las poblaciones mayas de Yucatán y Guatemala, también incursionó en ciertas localidades de Chiapas, donde concurrieron los talentos de jóvenes investigadores como Alfonso Villa Rojas o el propio Sol Tax (Medina, 2015). ${ }^{2}$

A lo largo de la década de 1940, en México la Escuela Nacional de Antropología e Historia recibió apoyo a la formación e investigación a través de las becas proporcionadas por diversas fundaciones de Estados Unidos, como la Viking, la Rockefeller, la Guggenheim y la Carnegie, entre otras. Así fue como en 1942 Sol Tax, siendo profesor del Departamento de Antropología de la Universidad de Chicago, llevó a Los Altos de Chiapas a un grupo de estudiantes de la primera generación de inscritos en dicha escuela, entre los que se encontraban Calixta Guiteras Holmes y Ricardo Pozas Arciniega, quienes hasta la fecha son reconocidos por la calidad y originalidad en sus investigaciones sobre San Pedro Chenalhó y San Juan Chamula (Guiteras, 1965; Pozas, 1948). Esto dijo Sol Tax con respecto a su experiencia en México:

Yo estuve allí [en la Escuela Nacional de Antropología e Historia], en 1942, como profesor visitante; ocho estudiantes -Cali[xta Guiteras] entre ellos- me acompañaron a Zinacantán, aldea chiapaneca, para adiestrarse en el trabajo de campo, en antropología social. Al año siguiente volvió ella a Chiapas (lo mismo que otros dos estudiantes) a realizar investigaciones independientes en las aldeas (Tax, 1965: 281).

\footnotetext{
${ }^{1}$ La investigación para este artículo fue conducida siendo Becario del Programa de Becas Posdoctorales en la UNAM, Centro de Investigaciones Multidisciplinarias sobre Chiapas y la Frontera Sur, México, y asesorado por el doctor Gabriel Ascencio Franco.

${ }^{2}$ Para mayores detalles de la Institución Carnegie de Washington, Robert Redfield, Sol Tax y su influencia en la antropología guatemalteca véase el excelente trabajo de Letona (2019: 131-184).
}

EntreDiversidades. Revista de Ciencias Sociales y Humanidades, vol. 8, núm. 1 (16), enero-junio 2021. Páginas: 186 - 211 ISSN-e: 2007-7610. https://doi.org/10.31644/ED.V8.N1.2021.A08 
Paralelamente, empezó a cobrar relevancia en Chiapas la labor evangelista del Instituto Lingüístico de Verano, que con Marianna Slocum ${ }^{3}$ al frente emprendió la tarea de aprendizaje de la lengua tzeltal de Oxchuc para la traducción y transmisión del Nuevo Testamento (Medina, 2015). Si bien Calixta Guiteras y sus compañeros no tuvieron mayores inconvenientes en las primeras visitas que hicieron a Los Altos de Chiapas de la mano de Sol Tax, no sucedió lo mismo cuando ella quiso regresar diez años más tarde. Con ocasión de estudiar la visión del mundo de un indígena - labor encomendada por el propio Robert Redfield-, la investigadora cubana volvió al pueblo tzeltal de San Juan Cancuc, del que tras unos pocos días fue expulsada bajo los gritos: “¡Fuera, bruja, fuera, evangelista!”, pues sus habitantes pensaban que era amiga de Marianna (Tax, 1965: 282). Esto la condujo a replantear su investigación en San Pedro Chenalhó, el pueblo donde su amistad con el indígena tzotzil Manuel Arias Sojom le permitió concebir Los peligros del alma. En este trabajo, como en otros de esta época, ya estuvo presente el tema del cambio cultural. Conceptos tales como "resistencia”, "aculturación” y "ladinización" fueron empleados para referirse a esos aspectos que acompañaban a la salida - o no- de indígenas de sus comunidades para formar parte de las masas de trabajadores de la nación mexicana (Guiteras, 1965: 9). ${ }^{4}$

Esos fueron los años en que empezaron a plantearse los fundamentos de la antropología activa (action anthropology, distinta de la antropología aplicada), de la mano de los proyectos regionales de investigación. A mediados de la década de 1940 Sol Tax contaba que, tras diez años de trabajo antropológico para la Institución Carnegie de Washington, había adquirido muchos conocimientos sobre la región de Los Altos de Chiapas y Guatemala. Sin embargo, y pese a que nadie se lo había requerido, él pensaba que tal vez su experiencia podía ser útil a los administradores para resolver problemas locales. Confesó entonces que habían sido sus jóvenes estudiantes quienes, en el desarrollo de una salida de campo a uno de los pueblos indígenas de Chiapas, y ante la evidencia de la pobreza, enfermedad y explotación en que estos vivían, lo habían increpado diciéndole que querían saber cómo podía él haber visto lo que ellos estaban viendo y no haber hecho nada al respecto (Tax, 1945). Esta fue la semilla de otra empresa de investigación, esta vez en tierras estadounidenses, conocida como el Proyecto Fox, del que por cierto existe una historia documental que narra el desarrollo de la antropología activa, tal y como fue diseñada y pensada con respecto a la comunidad contemporánea de los indígenas Fox, cercanos a Tama (Iowa), y que se desarrolló desde el verano de 1948 hasta el de 1959 (Gearing, Netting y Peatti, 1960).

Para entonces, ya había sido identificada la necesidad de formular investigaciones que se ocuparan de áreas más amplias de Chiapas, con el objetivo de elaborar monografías pormenorizadas de los pueblos junto a una descripción detallada de las lenguas habladas en ellos. El proyecto Man in Nature identificó ese vacío de conocimiento y se propuso estudiar

\footnotetext{
${ }^{3}$ Los avatares de su experiencia misionera en tierras chiapanecas pueden encontrarse en The Good Seed (1988).

${ }^{4}$ Para otra investigación, cabría considerar las razones por las cuales las etnografías concentradas en la "cosmovisión" tuvieron mayor difusión e impacto —al menos en los años de 1960— que aquellas enfocadas en el "cambio cultural”. A propósito, sobre este último concepto ha reaparecido un renovado interés. Una referencia clásica para su análisis es Williams (1966); un balance más reciente de la discusión puede verse en Eriksen (2007).
}

EntreDiversidades. Revista de Ciencias Sociales y Humanidades, vol. 8, núm. 1 (16), enero-junio 2021. Páginas: 186 - 211 ISSN-e: 2007-7610. https://doi.org/10.31644/ED.V8.N1.2021.A08 
las comunidades mayenses de Los Altos de Chiapas con un equipo que, entre otros, convocó a antropólogos, geólogos, geógrafos y botánicos. Como veremos, muchos de sus presupuestos teóricos iniciales, como por ejemplo los relativos a las comunidades corporadas, tuvieron que ser replanteados con la finalidad de dar cuenta de la variabilidad regional y la profundidad histórica de los fenómenos estudiados (Medina, 2015).

Fueron pocos los trabajos que se publicaron como resultado del proyecto, destacando aquellos reunidos en el libro Ensayos de antropología en la zona central de Chiapas (McQuown y Pitt-Rivers, 1970). No obstante, hasta el día de hoy, la mayor parte de los materiales producidos por el equipo de trabajo permanece en el olvido. Con el presente artículo pretendo ofrecer una mirada de conjunto a los estudios monográficos realizados en la primera etapa (1956 a 1959), enfocándome en los documentos reunidos en el informe presentado a los patrocinadores de la National Science Foundation y las autoridades de la Universidad de Chicago (Report on the Man in Nature Project).

\section{El reporte}

Las notas que se recogen en el presente artículo se basan en el reporte que el equipo de investigadores presentó en 1959 a la Universidad de Chicago para dar cuenta de las actividades desarrolladas desde 1956. De entrada, conviene aclarar la estructura de este documento. Estaban programadas cuatro partes, la primera de ellas titulada "Los hallazgos", la segunda, "Los datos", la tercera, "Estudios complementarios" y, la cuarta, "Estudios complementarios (Lingüística)”. Esta última parte no fue incorporada en el reporte final (Report on the Man in Nature Project).

La primera parte del reporte recogió las generalidades, conclusiones e interpretaciones formuladas luego del análisis de los datos concretos. Se trató del más corto de los tres apartados y contenía apenas cuatro trabajos. En apoyo de los argumentos defendidos a lo largo de los textos, esta parte inicial fue acompañada de numerosos mapas, figuras, esquemas y cuadros, los cuales reunían y organizaban copiosos datos relativos a infinidad de temáticas.

La segunda parte del reporte se distinguió de la anterior en el contenido del que trataban los textos. En lugar de ofrecer análisis concluyentes o grandes generalizaciones, este volumen reunió tres tipos de contribuciones que, o se ocuparon de un tema en específico comparando varios pueblos — fuera este el hábitat, la vegetación, la lingüística, la arqueología, la etnohistoria, la organización social o los procesos de cambio sociocultural一, o se sumergieron en las características específicas de cada pueblo — como se hizo con Amatenango del Valle, Aguacatenango, Chanal, Teopisca, Venustiano Carranza y Villa Las Rosas- o, en su lugar, plantearon problemas de investigación para resolver en el futuro - como sucedió con algunas cuestiones que tenían que ver con procesos históricos, tenencia de la tierra o antropología física-. En cuanto a la cantidad de trabajos, esta parte ocupó el primer lugar, con diecisiete, si bien el tercer apartado fue el más voluminoso de todos.

La última parte del reporte presentó información más detallada, con una cantidad de quince trabajos. Los asuntos ofrecidos fueron los siguientes: nuevas etnografías, para pueblos como Aguacatenango, Huixtán y Oxchuc; temas específicos al interior de un pueblo, tales

EntreDiversidades. Revista de Ciencias Sociales y Humanidades, vol. 8, núm. 1 (16), enero-junio 2021. Páginas: 186 - 211 ISSN-e: 2007-7610. https://doi.org/10.31644/ED.V8.N1.2021.A08 
como el control y la estructura social, los marcadores de aculturación, el pluralismo cultural, las prácticas de curación y brujería, el reclutamiento de líderes o la economía; también, aplicación de herramientas metodológicas novedosas, por ejemplo, el cálculo de la distancia dialectal, el método histórico en antropología social y los modelos de toma de decisiones o elección económica; o igualmente, trabajos comparativos sobre asuntos como la estructura social o el uso de nombres calendáricos y apellidos indígenas.

Los pueblos que concentraron la atención de los investigadores fueron Aguacatenango, Amatenango del Valle, Chanal, Huixtán, Oxchuc, Teopisca, Venustiano Carranza y Villa Las Rosas —estos dos últimos antes conocidos como San Bartolomé de Los Llanos y San Miguel Pinola (Mapa 1) —. La cantidad total de trabajos que recogió este primer reporte de investigación fue de 36, dentro de los cuales — hasta donde tenemos noticia - fueron publicados en versiones muy similares tres de ellos y otros tantos ampliados o resumidos para su publicación, mientras que la gran mayoría de estos, 30, por lo pronto no están disponibles para el público en general. El total de autores incluidos fue de 18, de los cuales cuatro eran mujeres y los 14 restantes hombres. En términos de su aporte al proyecto, John Hotchkiss fue el investigador que más contribuyó, participando en ocho de los documentos presentados, quien fue seguido por Muriel Verbitsky y John Baroco, con cinco y tres trabajos respectivamente (Tabla 1).

La nómina de los investigadores fue bastante diversa, involucrando geógrafos, botánicos, antropólogos, arqueólogos, lingüistas e historiadores. La gran mayoría de los participantes en esta primera fase del proyecto eran de nacionalidad estadounidense, siendo la única excepción Muriel Verbitsky, originaria de Argentina, formada en México y Estados Unidos y posteriormente casada con el también antropólogo Robert Hunt. ${ }^{5}$ La segunda fase del proyecto (1959-1962) amplió el espectro de académicos a Europa y Latinoamérica, periodo que acá no consideramos dado que requiere un análisis pormenorizado. ${ }^{6}$

\footnotetext{
${ }^{5}$ Muriel Eva Verbitsky de Hunt (1934-1980) nació en Argentina, a donde sus padres habían migrado procedentes de Rusia. La familia posteriormente se trasladó a la Ciudad de México, que durante los primeros años de la década de 1950 sería el lugar en el que Eva vivió su juventud: terminó la secundaria en la Universidad Femenina de México, estudió antropología en la Escuela Nacional de Antropología e Historia y obtuvo su primera experiencia profesional al trabajar con Roberto Weitlaner en el Museo Nacional de Antropología. Como parte de su experiencia en México, tuvo la oportunidad de estudiar a los cuicatecos y la región mixteca de Oaxaca, junto con Kimball Romney. A partir de 1957, Muriel ingresó en la Universidad de Chicago para continuar con sus estudios de posgrado en antropología bajo la dirección de Robert Adams, Fred Eggan y Eric Lobo, consiguiendo su maestría en 1959 y el doctorado en 1962, con una tesis sobre las dinámicas del grupo doméstico en dos pueblos tzeltales. En 1960 la antropóloga contrajo matrimonio con su colega Robert Hunt y unos años después empezó a dar clases en la Universidad de Chicago, para finalmente establecerse como catedrática de la Universidad de Boston. Esta investigadora ha sido reconocida por sus contribuciones a la etnohistoria y la antropología simbólica, destacándose su libro The Transformation of the Hummingbird: Cultural Roots of a Zinacantecan Mythical Poem (1977). Curiosamente, es poco lo que se sabe de la participación de Eva Hunt en el proyecto Chicago, pese a ser una de las personas que más contribuyó, aportando cinco textos para este reporte inicial. Mayores detalles biográficos en: Bohannan (1981); Departments \& People (1980); Gacs et al. (1988: 40); y Enciclopedia.com (2020).

${ }^{6}$ Anteriormente he ofrecido un contexto histórico del desarrollo de la antropología en México para la comprensión del proyecto dirigido desde la Universidad de Chicago. De igual modo, he presentado mayores detalles con respecto a los objetivos e integrantes del proyecto. Asimismo, he contrapuesto la lectura ortodoxa que se ha hecho de esta empresa académica con una que he denominado "revisionista". Allí también he ahondado en los orígenes e implicaciones de
}

EntreDiversidades. Revista de Ciencias Sociales y Humanidades, vol. 8, núm. 1 (16), enero-junio 2021. Páginas: 186 - 211 ISSN-e: 2007-7610. https://doi.org/10.31644/ED.V8.N1.2021.A08 
Mapa 1. Distribución y localización proyectadas de los pueblos tzeltales y tzotziles hacia 1610

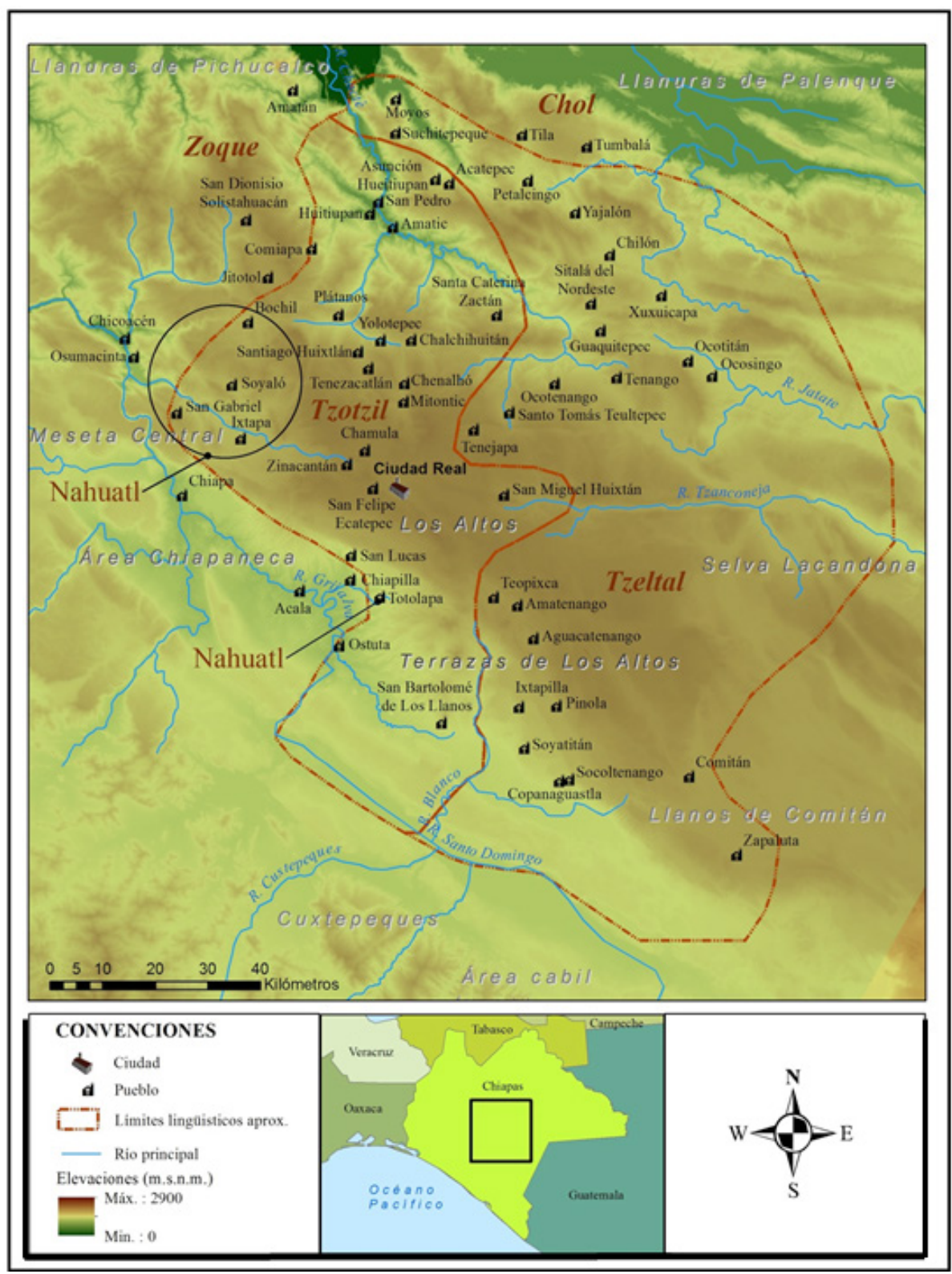

Fuente: Elaborado por Mauricio Arango Puerta. Con base en: RLSC-ST, Caja 104, exp. 5; CALNEK, "Distribution and localization".

\begin{abstract}
etiquetas como "culturalista" y "funcionalista" en la consideración de sus productos académicos, así como también en la revaloración del impacto de la "escuela británica de antropología social". Por último, he señalado y empleado los materiales del proyecto como fuentes históricas para la comprensión de los procesos de cambio cultural —en particular la permanencia y el abandono de lenguas mesoamericanas - experimentados por las poblaciones tzetales y tzotziles de Chiapas. Para mayor información, consultar Barrera Aguilera (2019a y 2019b).
\end{abstract}

EntreDiversidades. Revista de Ciencias Sociales y Humanidades, vol. 8, núm. 1 (16), enero-junio 2021. Páginas: 186 - 211 ISSN-e: 2007-7610. https://doi.org/10.31644/ED.V8.N1.2021.A08 
Tabla 1: Lista de trabajos recogidos en el primer reporte del Proyecto Chicago

\begin{tabular}{|c|c|}
\hline Autor(a)(es) & Título y extensión del trabajo \\
\hline WAGNER, Philip y John HOTCHKISS & "Habitat and Human Activity", 8 pp. \\
\hline ADAMS, Robert y Norman A. MCQUOWN & $\begin{array}{c}\text { "Pre-History and Post-Conquest Developments", } 7 \\
\text { pp. }\end{array}$ \\
\hline $\begin{array}{l}\text { NASH, Manning, Muriel VERBITSKY, } \\
\text { John HOTCHKISS y Norman A. } \\
\text { MCQUOWN }\end{array}$ & $\begin{array}{l}\text { "Present-Day Socio-Cultural-Linguistic- } \\
\text { Ethnohistorical Correlations", } 14 \text { pp. }\end{array}$ \\
\hline MCQUOWN, Norman A. & "Overview and Preview", 9 pp. \\
\hline WAGNER, Philip & "Habitat", 21 pp. \\
\hline KAPLAN, Lawrence & "Vegetation Dynamics", 14 pp. + anexos. \\
\hline ADAMS, Robert & "Archeological Reconnaissance", 58 pp. + anexos. \\
\hline $\begin{array}{l}\text { MAYERS, Marvin K., Yvone HAJDA } \\
\text { y Norman MCQUOWN }\end{array}$ & $\begin{array}{c}\text { “Tzeltal-Tzotzil Linguistics: Description, } \\
\text { Distributions, Relations", } 11 \text { pp. }+39 \text { pp. de } \\
\text { anexos. }\end{array}$ \\
\hline CALNEK, Edward E. & "Ethnohistorical Notes", 10 pp. \\
\hline NASH, June & "Amatenango del Valle", 62 pp. + anexos. \\
\hline VERBITSKY, Muriel E. & “Aguacatenango", 53 pp. \\
\hline CALNEK, Edward E. & “Chanal”, 20 pp. \\
\hline HOTCHKISS, John & “Teopisca”, 49 pp. \\
\hline DAY, Christopher & "Venustiano Carranza", 19 pp. \\
\hline HOTCHKISS, John & $\begin{array}{c}\text { "Chanal, Teopisca and Venustiano Carranza", } 15 \\
\text { pp. }\end{array}$ \\
\hline VERBITSKY, Muriel & $\begin{array}{l}\text { "Comparative Social Organization of the Transect } \\
\text { Communities", } 20 \text { pp. + anexos. }\end{array}$ \\
\hline VERBITSKY, Muriel y John HOTCHKISS & “Appendix I: Historical Problems”, 11 pp. \\
\hline HOTCHKISS, John & $\begin{array}{l}\text { "Appendix II: Comparative Land Tenure Systems", } \\
6 \text { pp. }\end{array}$ \\
\hline & “Appendix III: Community Structures” \\
\hline FLANNERY, Kent & $\begin{array}{l}\text { "Notes on the Tzeltal-Tzotzil Physical } \\
\text { Anthropology", } 3 \text { pp. }\end{array}$ \\
\hline HOTCHKISS, John & "Villa Las Rosas", 7 pp. \\
\hline MILLER, Frank & $\begin{array}{l}\text { "Social Structure and Changing Medical Practices } \\
\text { in a Mexican Indian Community", } 7 \text { pp. }\end{array}$ \\
\hline METZGER, Duane & $\begin{array}{l}\text { "A Frame for Culture-in-Environment Studies", } 8 \\
\text { pp. }\end{array}$ \\
\hline MCQUOWN, Norman A. & $\begin{array}{l}\text { "Measures of Dialect Distance in Tzeltal-Tzotzil", } \\
\qquad 9 \text { pp. }+ \text { anexos. }\end{array}$ \\
\hline NASH, Manning & $\begin{array}{l}\text { "The Small-Scale Economy: The Context of } \\
\text { Economic Choice", } 13 \text { pp. anexos. }\end{array}$ \\
\hline
\end{tabular}

EntreDiversidades. Revista de Ciencias Sociales y Humanidades, vol. 8, núm. 1 (16), enero-junio 2021. Páginas: 186 - 211 ISSN-e: 2007-7610. https://doi.org/10.31644/ED.V8.N1.2021.A08 


\begin{tabular}{|c|c|}
\hline METZGER, Duane & $\begin{array}{l}\text { "A Preliminary Evaluation of Institutionalized } \\
\text { Social Control and Its Contribution to Cultural } \\
\text { Pluralism in the Highlands of Chiapas", } 21 \mathrm{pp} .\end{array}$ \\
\hline NASH, June & $\begin{array}{c}\text { "Social Structure and Social Organization in } \\
\text { Oxchuc, Chiapas", } 25 \text { pp. + anexos }\end{array}$ \\
\hline METZGER, Barbara & $\begin{array}{l}\text { "The Social Structure of Three Tzeltal } \\
\text { Communities: Omaha Systems in Change", } 35 \text { pp. } \\
\text { + anexos. }\end{array}$ \\
\hline RUBEL, Arthur & $\begin{array}{c}\text { "Changing Processes of Leadership Recruitment } \\
\text { in Venustiano Carranza (San Bartolomé de Los } \\
\text { Llanos), Chiapas", } 38 \text { pp. + anexos. }\end{array}$ \\
\hline MILLER, Frank & $\begin{array}{c}\text { "Preliminary Ethnographic Report on Huistán, } \\
\text { Chiapas", } 33 \text { pp. }\end{array}$ \\
\hline VERBITSKY, Muriel E. & $\begin{array}{c}\text { "Residence Patterns in a Tzeltal Community", } 50 \\
\text { pp. }\end{array}$ \\
\hline BAROCO, John & $\begin{array}{l}\text { "El Método Histórico en Antropología Social: Los } \\
\text { Apellidos de Chanal", } 19 \text { pp. }\end{array}$ \\
\hline BAROCO, John & $\begin{array}{l}\text { "Notes on the Use of Calendarical Names in } \\
\text { Sixteenth Century Chiapas", } 16 \text { pp. }\end{array}$ \\
\hline BAROCO, John & $\begin{array}{l}\text { "Tzotzil-Tzeltal Nomenclature and Social } \\
\text { Structure", } 17 \text { pp. }\end{array}$ \\
\hline NASH, Manning & $\begin{array}{l}\text { "Witcheraft as Social Process in a Tzeltal } \\
\text { Community", } 8 \text { pp. }\end{array}$ \\
\hline HOTCHKISS, John & $\begin{array}{c}\text { "Markers of Acculturation in a Ladino-Indian } \\
\text { Town", } 7 \text { pp. }\end{array}$ \\
\hline
\end{tabular}

Fuente: Report on the Man in Nature Project (1956-1959).

\section{Los pueblos: etnografías y temas específicos}

\section{Aguacatenango}

Muriel Verbitsky contribuyó al proyecto con uno de los trabajos monográficos. Como muestra de las transformaciones que estaba experimentando el pueblo de Aguacatenango ella se enfocó en la lengua y el parentesco. Por un lado, los hijos de gente "progresista" aprendían el español a una edad temprana. Para los aguacatecos el bilingüismo estaba asociado con la inteligencia, mientras que la investigadora lo consideró como un síntoma de la aculturación (Verbitsky, 1959a: 2-3).

Por otro lado, el sistema de parentesco estaba en pleno proceso de transformación. Verbitsky supuso que en Aguacatenango anteriormente predominaba el tipo patrilineal y estaba dando muestras de cambio hacia uno bilateral. Había aspectos que hacían que Aguacatenango se acercara al modelo ideal de organización social en la región. El matrimonio era endogámico a cada uno de los dos barrios ubicados a lado y lado de la iglesia. Otra muestra era la existencia en el pueblo 
de un ayuntamiento que aplicaba el "código moral tradicional", como también la presencia de una organización religiosa compuesta por 14 cargos ordenados jerárquicamente de acuerdo con la edad de cada uno de sus detentores (Verbitsky, 1959a: 4 y 21).

No obstante las anteriores muestras de "organización tradicional”, la autora dedicó un buen espacio de su argumentación a ilustrar innovaciones como la influencia ladina —o no indígenaen el estilo de construcción de las casas, la obtención de créditos a través de los hombres más ricos, la introducción de técnicas como el arado y la irrigación o la incorporación de la cría de ganado a la economía local (Verbitsky, 1959a: 32 y 43-45).

Muriel Verbitsky brindó numerosos testimonios de los movimientos y conexiones presentes en el pueblo de Aguacatenango. Además de unas familias que se habían marchado a vivir a Teopisca, aproximadamente desde 1930, grupos de aguacatecos se habían estado moviendo hacia El Puerto, unas antiguas tierras comunales ubicadas en clima cálido. De la misma manera, la gente de Aguacatenango sostenía mutuas visitas religiosas y comerciales con sus vecinos de Pinola y Teopisca, y existía un flujo constante de trabajadores aguacatecos hacia las plantaciones de cańa de azúcar ubicadas en el recién creado ingenio de Pujiltic (Verbitsky, 1959a: 48-49).

En esta monografía Muriel Verbitsky lanzó una aguda crítica a las actividades desarrolladas por el Instituto Nacional Indigenista (INI). En opinión de esta antropóloga, hasta ese momento el impacto de las políticas impulsadas por el instituto era mínimo en Aguacatenango, como consecuencia de que este no había considerado la organización social de la comunidad al momento de plantear sus programas. La investigadora agregaba que los delegados elegidos para representar a los aguacatecos ante la institución eran demasiado jóvenes y marginales dentro de la comunidad (Verbitsky, 1959a: 50).

El otro trabajo de Muriel Verbitsky sobre Aguacatenango es en realidad su tesis de maestría en antropología presentada a la Universidad de Chicago, considerada como una de las investigaciones pioneras en la implementación del ciclo doméstico para el análisis de los patrones de residencia en pueblos mesoamericanos. La autora se enfocó en las formas de patrocinio de los nuevos hogares, las cuales variaban según las historias individuales (Verbitsky, 1959b: 1-6 y 17-27).

Otro aporte significativo de la investigación realizada por Muriel Verbitsky en Aguacatenango es haber comparado los patrones ideales con las prácticas reales. En este sentido, la antropóloga reservó un lugar importante a la consideración de la evidencia numérica, lo que le permitió descubrir aquellos patrones de comportamiento practicados por las personas pero que no eran expresados conscientemente. Este tipo de aproximación hizo posible identificar las tensiones y desviaciones a la norma. Ese era el caso de la transición conflictiva desde una residencia compuesta, que reunía a los padres junto a un hijo casado y su mujer e hijos, hacia un hogar de tipo nuclear independiente. Este enfoque también fue útil para comprender las orillas del pueblo como áreas de refugio para parejas que se desviaban de la norma, o que habían migrado recientemente desde lugares como Chamula, El Puerto o La Palizada (Verbitsky, 1959b: 31 y 39).

Adicionalmente, existían violaciones a la regla de la endogamia de barrio. Un caso particular era el de los matrimonios entre Aguacatenango y El Puerto, una colonia que para el momento del estudio ya era considerada como una unidad social independiente. Todavía más curioso resultaba el caso de La Palizada, un paraje de tierras altas, que representaba una última opción para casar

EntreDiversidades. Revista de Ciencias Sociales y Humanidades, vol. 8, núm. 1 (16), enero-junio 2021. Páginas: 186 - 211 ISSN-e: 2007-7610. https://doi.org/10.31644/ED.V8.N1.2021.A08 
las hijas de las familias numerosas y pobres, si bien los matrimonios eran un desprestigio familiar por cuenta de la penuria de los maridos (Verbitsky, 1959b: 40-43).

El antropólogo Duane Metzger también estudió Aguacatenango. El principal argumento de su trabajo es que aún luego de haberse producido la Revolución el pueblo mantuvo una cantidad considerable de autonomía política con respecto a las instituciones del estado de Chiapas y de la república mexicana, así que logró solucionar la mayor parte de sus pleitos por medio de sus propias autoridades. Según él, hasta 1954 el secretario del pueblo había sido un indígena que hablaba español y sabía manipular las formas ladinas. Después de ese año, el puesto fue asumido por el maestro de escuela, que era ladino. ${ }^{7}$ Sin embargo, debido a los abusos de autoridad, el presidente no fue reelegido y el profesor fue expulsado del pueblo, así que la comunidad reaccionó fervorosamente a las innovaciones que se habían pretendido implementar (Metzger, 1959: 8-9 y 12-13).

La conclusión de Duane Metzger es que los mecanismos de control interno habían permitido conservar la autonomía social y cultural de Aguacatenango. Un aspecto que cabe resaltar es que el documento contiene numerosos casos judiciales que ilustran los dispositivos locales de resolución de conflictos (Metzger, 1959: 14-21).

\section{Amatenango del Valle}

June Nash afirmó que Amatenango del Valle era una comunidad unida por lazos de sangre y costumbre, viviendo en su propio territorio y compartiendo una particularidad étnica. Lo curioso del caso es que, prácticamente a renglón seguido, la antropóloga mencionó las migraciones desde otros pueblos de Los Altos de Chiapas, como Huixtán, hacia los barrios periféricos a la cabecera y las colonias rurales más apartadas. Otro de los aspectos que cuestionaba la consideración de Amatenango como una sociedad homogénea era la existencia de un grupo de ladinos pobres, y provenientes de Michoacán, dedicados a aserrar madera, con quienes los amatenangueros interactuaban de manera recurrente (Nash, J., 1959a: 1-4).

Lo anterior no quiere decir que la influencia del mundo ladino en el pueblo de Amatenango fuera recibida de manera pasiva. La antropóloga June Nash mencionó la presencia del INI, como también la del maestro de escuela y la del párroco. No obstante, en una comunidad donde la brujería gozaba de alto prestigio, el desempeño del médico encontraba grandes dificultades. De igual modo, el maestro de escuela, por el solo hecho de ser ladino, era muy resistido. Además, cabe resaltar que desde hacía cuatro años no había un cura permanente en el pueblo (Nash, J., 1959a: 5-9).

Amatenango del Valle parecía ser una sociedad abierta a las relaciones con otros grupos. Por una parte, los amatenangueros obtenían de los ladinos teopiscanecos manufacturas, préstamos, curanderos, padrinos y compadres. Por otra, desde hacía mucho tiempo, los amatenangueros iban a la fiesta de la Natividad en Aguacatenango, y los habitantes de este último pueblo visitaban a los del primero con motivo de la fiesta de Santa Lucía (Nash, J., 1959a: 9-11).

Los amatenangueros intercambiaban sus piezas de alfarería por frutos en Villa Las Rosas y textiles en Venustiano Carranza, además de que muchos de ellos también alquilaban su trabajo

${ }^{7} \mathrm{Si}$ bien en el contexto centroamericano el término ladino ha cambiado a lo largo del tiempo, para mediados del siglo XX los académicos lo empleaban para referirse a la población no india (Rodas, 2004).

EntreDiversidades. Revista de Ciencias Sociales y Humanidades, vol. 8, núm. 1 (16), enero-junio 2021. Páginas: 186 - 211 ISSN-e: 2007-7610. https://doi.org/10.31644/ED.V8.N1.2021.A08 
en algunas fincas de esos dos municipios. De igual modo, mucha de la cerámica y del trigo producidos en tierras de Amatenango eran vendidos en las ciudades de San Cristóbal de Las Casas y Comitán de Domínguez, mercados de los cuales se obtenían diferentes productos (Nash, J., 1959a: 11-13).

Amatenango estaba dividido en dos barrios o mitades endogámicas: Aconantic y Anantic. La investigadora dedicó buena parte del documento a estudiar la manera en que el pueblo estaba estructurado, concluyendo que la comunidad estaba tejida apretadamente, condición manifiesta en grupos barriales compuestos de padres e hijos, asimismo que de hermanos y afines (Nash, J., 1959a: 15-34).

En teoría, la tierra pertenecía a la comunidad y era inalienable. En la práctica, y a pesar de la fuerte resistencia a las ventas de propiedades, una alta proporción de tierras dentro de los límites del municipio se había distribuido en unas cuantas familias. Aunque el pueblo tenía mecanismos que apuntaban a mantener fuertemente cohesionados a sus integrantes, como la propia June Nash propuso, lo cierto es que Amatenango no era una comunidad completamente autosuficiente. La localidad dependía de una red de mercado para proveerse de dinero y así poder acceder a mayor variedad de alimentos y servicios (Nash, J., 1959a: 43 y 47-50).

En Amatenango del Valle también se asoció la brujería con el control de la desigualdad entre las personas. La antropóloga sostuvo que los amatenangueros se cuidaban de no sobrepasarse en cuanto a innovación o tamańo al momento de construir sus casas (tener paredes de tabique y techo de zinc podría despertar la envidia de los vecinos y, por lo tanto, ser objeto potencial de brujería). Un aspecto que llamó la atención de June Nash, y que está íntimamente relacionado con el papel de la brujería, fue el de las ceremonias de curación. Esta práctica prestaba la función de promover las relaciones armónicas dentro del hogar, o también entre los vecinos del pueblo. Las ceremonias cumplían una labor fundamental al permitir que los miembros del grupo airearan sus quejas o demostraran su apoyo a uno de los miembros en disputa (Nash, J., 1959a: 52 y 59-61).

La investigadora reservó unas cuantas páginas de su escrito al estudio de la jerarquía de cargos civiles-religiosos, una organización que se encontraba conformada por hombres adultos que servían como un deber público y sin recibir remuneración. Dicha jerarquía tenía las funciones de preservar el orden comunitario, exigir el trabajo de la comunidad en proyectos públicos, resolver disputas entre personas, organizar las fiestas y visitas religiosas a otros pueblos y también a las cuevas, además de negociar con los ladinos y el gobierno mexicano (Nash, J., 1959a: 52-54).

El reporte también incluyó un trabajo de Manning Nash que se ocupa de la creencia y práctica de la brujería en el pueblo de Amatenango. Los datos recabados le permitieron al antropólogo identificar la existencia de una teoría sobre la brujería que era compartida por los amatenangueros, así como también entrever un procedimiento que, por una parte, permitía encontrar y eliminar al brujo y, por otra, juzgar a su verdugo (Nash, M., 1959a).

La interpretación de Manning Nash iniciaba por señalar que los hombres de Amatenango creían que algunos de ellos tenían unas contrapartes animales llamadas naguales. La fuerza del animal era ambigua, pues dependía de los fines que persiguieran sus poseedores, ya fuera para curar las enfermedades, o bien para provocarlas. Quienes perseguían el último de los fines señalados eran considerados como brujos. No obstante, había un alto grado de incertidumbre que rodeaba

EntreDiversidades. Revista de Ciencias Sociales y Humanidades, vol. 8, núm. 1 (16), enero-junio 2021. Páginas: 186 - 211 ISSN-e: 2007-7610. https://doi.org/10.31644/ED.V8.N1.2021.A08 
la identificación de estos: si bien todos los curanderos tenían naguales, algunos hombres que los poseían no eran públicamente conocidos por la comunidad (Nash, M., 1959a: 1-2).

Manning Nash consideró que una de las claves para comprender este sistema de creencias en brujos consistía en determinar cuáles eran los procedimientos para identificar y eliminar a estos personajes. Cuando una persona estaba embrujada era porque padecía una enfermedad que no tenía cura. El paso siguiente era determinar por qué razón y quién produjo el embrujo: ¿acaso la persona embrujada despertó el rencor de otra? o ¿quizás fue el resultado de una situación de envidia, discusión, tacańería o prepotencia? Ante este panorama, el enfermo concluía que alguien lo estaba afectando y pedía a un curandero que intentara hablar con el nagual del hombre que se sintió ofendido. Si la negociación no rendía frutos, no había más remedio que eliminar al brujo a través de una emboscada propiciada por varias personas (Nash, M., 1959a: 3-4).

Luego venía el inconveniente de establecer si el asesinato estaba justificado. Casi siempre el acusado del asesinato era dejado en libertad tras comprobarse que se trataba de una persona cumplida y respetada. En cambio, el hombre asesinado era considerado como un violador de las normas e incluso su propia familia podía atestiguar que desde tiempo atrás había roto relaciones sociales con él (Nash, M., 1959a: 6-7).

Probablemente el aspecto más interesante de la interpretación ofrecida por Manning Nash es haber develado la existencia y funcionamiento de un mecanismo de fabricación del consenso. Por supuesto, se trataba de una maquinaria imperfecta, que dejaba cabos sueltos y podía desencadenar violencia futura (Nash, M., 1959a: 7).

Manning Nash encaró otro problema en un breve trabajo: ¿cómo analizar y cuantificar las economías de pequeña escala? Este investigador se acercó a esta problemática estudiando campesinos a través del trabajo de campo. Las principales actividades productivas que Manning identificó en Amatenango fueron la agricultura, la cerámica y la ganadería. La agricultura requería una tecnología básica para los cultivos de milpa y trigo, como también para los huertos ubicados junto a las casas. Algo similar encontró el estudioso para el caso de la alfarería, una actividad que, si bien era la especialidad de esta comunidad, tampoco necesitaba de una tecnología sofisticada para su realización (Nash, M., 1959b: 2-3).

Manning Nash se enfocó en comprender las diferencias productivas existentes entre los hogares alfareros de Amatenango. Él encontró un hecho revelador: desafiando toda lógica, los hogares más ricos no eran aquellos que se dedicaban a la producción cerámica, pues en realidad no requerían de ingresos adicionales, de tal modo que eran los hogares más pobres los que dependían de la alfarería para obtener ganancias, gracias a que se trataba de un oficio no remunerado y cubierto con mano de obra familiar (Nash, M., 1959b: 4-7).

Otro de los aportes de la investigación emprendida por Manning Nash es haber hallado elementos que le permitieron cuestionar los trabajos que habían pretendido analizar los hogares en términos de empresas. El investigador encontró que las elecciones de los amatenangueros no se reducían a la maximización de resultados. Al momento de decidir sobre aspectos relativos a la economía familiar, uno de los principios que ellos tenían en cuenta era la equivalencia de riqueza. Este antropólogo identificó la existencia de mecanismos de nivelación social que impedían la expansión de las economías familiares más allá de ciertos límites, entre ellos: un bajo nivel

EntreDiversidades. Revista de Ciencias Sociales y Humanidades, vol. 8, núm. 1 (16), enero-junio 2021. Páginas: 186 - 211 ISSN-e: 2007-7610. https://doi.org/10.31644/ED.V8.N1.2021.A08 
tecnológico y cantidad de tierra limitada; la fragmentación de la propiedad por herencia; la inversión de tiempo y recursos en el desempeño de oficios comunales; y el gasto forzoso en actividades rituales en función de la riqueza. Dentro de las sanciones negativas para quienes sobrepasaban dichos límites se encontraban la brujería, el chisme y la envidia (Nash, M., 1959b: 8-11).

No obstante lo anterior, Manning Nash —en aras de tratar de atender a los factores sociales y culturales - tiende a generalizar el comportamiento de los amatenangueros ante ciertas situaciones. No termina de ser del todo convincente el modelo de una comunidad cuya naturaleza es ser corporada y económicamente equivalente, como tampoco los supuestos mecanismos de nivelación y castigo que entran a operar si se traicionan los universales igualitarios y homogéneos. Adicionalmente, en el texto se propone que los hombres tienen una alta preferencia por el ocio frente al trabajo fuera de la agricultura tradicional (Nash, M., 1959b: 12). Además de estereotipada, la imagen que el analista transmite de Amatenango es demasiado estática, pues desconoce múltiples migraciones por cuestiones laborales y de escasez de tierras.

\section{Chanal}

Edward Calnek incorporó algunos antecedentes de tipo histórico en su descripción del pueblo de Chanal. Si bien de entrada este académico destacó que al momento del análisis la población era mayoritariamente hablante de tzeltal y se identificaba como indígena, no omitió mencionar que con anterioridad unas pocas familias ladinas se habían establecido en la cabecera, pero posteriormente fueron forzadas a salir de allí en los años de 1940. No obstante, este autor ubicó el origen de Chanal como un asentamiento conformado en la primera mitad del siglo XIX por una colonia de personas provenientes de Oxchuc (Calnek, 1959: 1).

Chanal tenía la apariencia de un pueblo nucleado. Sin embargo, no siempre fue así, pues antes de 1930 la mayoría de las personas habitaban en parajes desperdigados a lo ancho de los campos. Parte de dicha disposición dispersa de los asentamientos seguía manteniéndose hacia los años de 1960. De hecho, entonces existía una clara distinción entre la sección de arriba del pueblo, caracterizada por sus suelos pedregosos e infértiles y sus ranchos ubicados a mayor distancia de la cabecera, y la sección de abajo, situada en clima cálido, con tierras menos pedregosas y más fértiles, y donde sus fincas estaban localizadas más cerca del asentamiento nuclear. Además de los parajes, Chanal también contaba con una colonia rural denominada Siberia. Y, en cierto grado, el pueblo de La Palizada —en cercanías de Aguacatenango- podía considerarse como otra colonia de Chanal, dado que allí residían cerca de 250 chanaleños que habían sido expulsados de su pueblo por supuestos actos de brujería. Por todo lo anterior, y pese a la existencia de una cabecera, Chanal se ajustaba a las descripciones de lo que en aquel momento los investigadores del proyecto denominaron como un "pueblo vacío". No en balde, era una práctica común que los hombres pasaran cinco o seis días a la semana fuera del núcleo urbano cuidando de sus tierras (Calnek, 1959: 2-3).

Otro de los rasgos característicos de Chanal era la variedad de intercambios comerciales que sostenía con poblaciones vecinas. Los chanaleños vendían huevos, pollos, cerdos, caballos y papas en Comitán, San Cristóbal y San Pedro (una colonia de Huixtán), y a cambio obtenían chile, cebolla, sal, panela, azúcar, ropa y medicinas. Además, otra muestra de la apertura del pueblo

EntreDiversidades. Revista de Ciencias Sociales y Humanidades, vol. 8, núm. 1 (16), enero-junio 2021. Páginas: 186 - 211 ISSN-e: 2007-7610. https://doi.org/10.31644/ED.V8.N1.2021.A08 
era que muchos chanaleños trabajaban en las fincas cercanas, como en El Paraíso, donde se alquilaban como peones para la explotación de caña y plátano (Calnek, 1959: 3).

En cualquier caso, Edward Calnek señaló que en Chanal también existían dos barrios endogámicos en cuanto a los matrimonios y derechos de uso sobre la tierra, ellos eran: alantic, "los de abajo", y jamaltic, "montañeros". Y como también ha sido mencionado para otros pueblos vecinos, los principales de Chanal ejercían gran parte de la autoridad, habiendo probado su idoneidad tras haber rotado por una serie de cargos municipales. De manera paralela, también fue registrado un sistema de cabildo indígena que estaba asociado al tratamiento ritual de asuntos agrícolas, como cuevas, rocas, pozos o manantiales sagrados. Una última característica que Chanal compartía con algunos de los pueblos de la región era la creencia en los naguales (Calnek, 1959: 5-15).

\section{Huixtán}

Acudiendo a los datos oficiales de 1950, Frank Miller señaló que los más de 7000 habitantes de Huixtán eran en su gran mayoría hablantes de la lengua tzotzil, si bien una pequeña parte de ellos dominaba el tzeltal. Es clave señalar que este investigador identificó la inexistencia de una asociación directa entre los hablantes de estas lenguas mesoamericanas y el uso de cierto vestido o la identificación con un grupo en particular. Había personas que hablaban tzeltal y vestían prendas ladinas, razón por la cual eran considerados como "revueltos" por aquellos que aún usaban el traje del pueblo, es decir, los que se identificaban a ellos mismos como "huixtecos". De manera similar, dentro de los hablantes de tzotzil los había tanto vestidos en prendas tradicionales como luciendo estilos ladinos. Si bien Huixtán compartía con otros pueblos el patrón de poblamiento correspondiente a un centro ladino rodeado de una periferia indígena, una particularidad era la presencia de población ladina tanto en parajes como en ranchos (Miller, 1959a: 1-3).

La razón de tal distribución espacial fue explicada por Frank Miller atendiendo a las migraciones. Antes de las reformas agrícolas introducidas por la administración de Lázaro Cárdenas, los ladinos se habían apoderado de las mejores tierras de Huixtán. Al momento en que se efectuó la investigación aún había algunos ranchos ladinos en el valle y existían evidencias de que varios ejidos del municipio fueron conformados con tierras anteriormente pertenecientes a las fincas. Por ejemplo, el ejido de Huajam, dentro del cual se encontraba el paraje de Yalcuc, fue fundado en tierras expropiadas a la finca Shuncalá. Antes de la creación del ejido en esas tierras habitaban unas cuantas familias de Chamula, Chanal y Huixtán. Los nuevos pobladores del lugar vinieron de la cabecera y parajes de Huixtán, así como también de la finca Shuncalá. Adicionalmente, a partir de esta misma propiedad fueron formadas otras dos colonias pobladas por hablantes de tzeltal que vestían a la manera ladina. También se encontraba el caso particular del ejido de Yashtinín, el cual estaba habitado por personas que se identificaban a sí mismas como huixtecos, y quienes eran identificadas como tales por personas de Yalcuc, aunque las primeras vestían a la manera ladina (Miller, 1959a: 3-4).

Como regla general, Frank Miller encontró un patrón de poblamiento disperso. Yalcuc era la única concentración poblacional de la colonia Huajam. Debido a lo reciente de la creación del poblado, la forma de residencia más común era de tipo neolocal. De igual manera, la existencia de un gran número de linajes en un mismo paraje parecía ser un fenómeno nuevo, que respondía a la formación de ejidos por personas provenientes de diferentes lugares. Esa situación había contribuido

EntreDiversidades. Revista de Ciencias Sociales y Humanidades, vol. 8, núm. 1 (16), enero-junio 2021. Páginas: 186 - 211 ISSN-e: 2007-7610. https://doi.org/10.31644/ED.V8.N1.2021.A08 
a que en Yalcuc se combinaran la existencia de linajes exógamos y un poblado endógamo. Otra de las particularidades de Yalcuc era que en lugar de una jerarquía de cargos civiles y religiosos, una asamblea general ratificaba lo que habían decidido los líderes del pueblo (Miller, 1959a: 7-14).

De acuerdo con Frank Miller, no podía decirse que Yalcuc fuera una sociedad "tradicional”, en términos de las condiciones materiales de existencia en las que vivían sus habitantes. Por una parte, la propiedad de la tierra era ejidal y los derechos de uso eran asignados individualmente y transferidos patrilinealmente. No obstante, existían grandes diferencias en cuanto a calidad y concentración de la tierra. Por otra, y de manera complementaria a las tierras dedicadas a la subsistencia, se cultivaba el trigo, en las cercanías de Huixtán, y el café, en el Soconusco. El antropólogo expuso de manera sobresaliente la migración estacional a las plantaciones de café, así como los costos del viaje y las ganancias obtenidas. Asimismo, presentó detalladamente las actividades involucradas en la explotación del trigo. Aquí fueron ofrecidos datos muy útiles en términos comparativos entre el maíz y el trigo, en cuanto a la productividad del suelo, las unidades de volumen y la variación de precios según las estaciones (Miller, 1959a: 17-21).

En este breve reporte Frank Miller mostró unas cuantas pinceladas con relación a la religión y el ciclo ceremonial. El principal foco de atención fue el calendario de fiestas católicas. Dentro de lo relativo a la celebración de San Miguel, el investigador identificó los rituales diferenciados que seguían indígenas y ladinos, y la visita de personas provenientes de Chamula y Tenejapa, quienes intercambiaban productos e interactuaban con la gente local, así como también con los ladinos y "revueltos" que llegaban desde fincas y parajes de Huixtán (Miller, 1959a: 25-26).

El antropólogo introdujo importantes observaciones con respecto a este punto de las relaciones sociales al interior del grupo y de este con el mundo exterior, las que a su vez le permitieron considerar aspectos relativos al cambio cultural. De entrada, cuestionó la interpretación que se ajustaba a los grados de aculturación, en parte porque esta perspectiva desconocía que aquello que suponía como nativo, en buena medida era fruto de la interacción con los españoles y de la experiencia colonial en su conjunto. En lugar de lo anterior, propuso definir grupos socioculturales de acuerdo con características locales que variaban, tales como el vestido, el trabajo en las fincas, la práctica del catolicismo y la participación en los asuntos de la comunidad. Este procedimiento permitió identificar un "grupo principal”, que vestía a la manera local, rechazaba el trabajo en las fincas y mostraba un catolicismo fuerte, además de una participación en la comunidad y los asuntos del municipio. En el otro extremo se encontraba un "grupo marginal", que difería con respecto a todos los criterios arriba descritos. También existían unos grupos intermedios, que se encontraban a mitad de camino entre los grupos mencionados (Miller, 1959a: 27-29).

En un texto complementario, Frank Miller profundizó sobre el impacto del Instituto Nacional Indigenista en el pueblo de Huixtán. El investigador enfocó su análisis a determinar la actividad del instituto como agente de cambio cultural, específicamente el establecimiento de una clínica y un puesto médico. Los resultados a los que llegó el antropólogo fueron sorprendentes. Contrario a lo que podría imaginarse, fueron los indígenas menos "aculturados" quienes estuvieron más dispuestos a recibir las medicinas modernas. La razón de dicho comportamiento residía en que para ellos tal auxilio gubernamental les permitía defender su identidad indígena frente al grupo ladino (Miller, 1959b: 4-7).

EntreDiversidades. Revista de Ciencias Sociales y Humanidades, vol. 8, núm. 1 (16), enero-junio 2021. Páginas: 186 - 211 ISSN-e: 2007-7610. https://doi.org/10.31644/ED.V8.N1.2021.A08 


\section{Oxchuc}

June Nash también estudió a profundidad las características políticas y sociales de Oxchuc. En este trabajo la investigadora resaltó el alejamiento de la población con respecto a un modelo inicial. Ella inició por señalar que Oxchuc era una comunidad alteña de poco más de 3000 personas, las cuales en su mayoría hablaban tzeltal, se identificaban como indígenas y habitaban en numerosos parajes articulados en torno a una cabecera con funciones ceremoniales y políticas (Nash, J., 1959b: 1).

La unidad de análisis de este artículo fue el paraje de Yochib, que se alejaba de ser una comunidad tradicional. La mayoría de las familias eran nucleares, la compra y venta de tierras eran prácticas bastante comunes, los linajes y clanes corporativos habían cedido su lugar a los hombres de prestigio y adicionalmente coexistían diferentes formas de trabajo, dentro de las que estaban incluidas las migraciones estacionales a las fincas del Soconusco (Nash, J., 1959b: 2-3 y 10-12).

Las características de Yochib resultaban más complejas considerando los aspectos espirituales, funerarios y políticos descritos por la antropóloga. Primero, la enfermedad implicaba culpa personal, bien por la violación del código moral o por una falencia en cubrir las expectativas de la sociedad, atrayendo en ambos casos el ejercicio de la brujería. Segundo, persistía la práctica de enterrar en tierras comunales a todos los hombres y mujeres no casados del grupo patrilineal. Tercero, todavía operaba buena parte de la jerarquía cívico-religiosa. Existían los "cabildos de milpa”, a quienes seguían los mayordomos, y a estos los capitanes de fiesta, quienes a su vez eran precedidos por los regidores, y por encima de todos ellos se encontraban los denominados principales. Este último grupo, a su vez, se encontraba dividido entre los dzunubiles, encargados del cuidado de las enfermedades, los chuycales, quienes atendían los asuntos de la iglesia, y el catinab y el okilcabil, ambos encargados de asuntos adivinatorios (Nash, J., 1959b: 17-21).

La antropóloga resaltó que en Oxchuc el oficio de presidente del ayuntamiento ahora era ocupado por un indígena joven que hablaba español, si bien continuaba rindiendo cuentas al catinab. De este modo, el viejo oficio de alcalde había cedido peso político para restringirse a asuntos meramente ceremoniales. La desintegración de la jerarquía tradicional provenía del conflicto de autoridad. El ayuntamiento dependía de las sanciones de la ley estatal y federal. En cambio, los líderes del calpul dependían de la sanción de la religión y la moralidad, basadas en el respeto, de acuerdo con la edad y el temor a la brujería (Nash, J., 1959b: 21-22).

El sistema de autoridad de Oxchuc también había sido alterado por la conversión rápida al protestantismo, que había iniciado en la década de 1940, pues significó una alternativa que socavaba la autoridad basada en la hechicería. Otro factor que contribuyó al colapso de los mecanismos de control interno fue la migración de muchos hombres jóvenes a las fincas, quienes fueron acusados de evadir responsabilidades sociales. En resumen, el control social había pasado de las manos de los viejos adivinos a las de los jóvenes líderes alfabetos y protestantes (Nash, J., 1959b: 24).

\section{Teopisca}

John Hotchkiss consideraba a Teopisca como una comunidad abierta en la que había movimientos de población hacia fuera y dentro de ella. En una sociedad caracterizada por una mayoría de habitantes ladinos el criterio de identificación de los indígenas no era ni el vestido ni la

EntreDiversidades. Revista de Ciencias Sociales y Humanidades, vol. 8, núm. 1 (16), enero-junio 2021. Páginas: 186 - 211 ISSN-e: 2007-7610. https://doi.org/10.31644/ED.V8.N1.2021.A08 
lengua, sino la manera como eran denominados por aquellos - ya fuera como "inditos" o como "muchachos" - y la forma cómo ellos mismos se identificaban —es decir, como "naturales"(Hotchkiss, 1959a: 1-2).

Otra de las particularidades que el antropólogo encontró en Teopisca fue el origen de quienes residían en el municipio. Los ocho barrios que componían la cabecera y las cuatro colonias que se encontraban en los alrededores del asentamiento nuclear estaban poblados por migrantes provenientes de Chamula y Huixtán (Hotchkiss, 1959a: 3-5).

John Hotchkiss destacó las migraciones como un aspecto constante en la historia de Teopisca. En primer lugar, propone el posible traslado de los indios teopiscanecos a Nicolás Ruiz en tiempos coloniales —algo que en realidad sucedió en el siglo XIX (Barrera, 2016; De Vos, 2010)—. Luego, apunta que la reforma agraria de la primera mitad del siglo XX generó las condiciones para migraciones a la zona, que derivaron en poblados permanentes o trabajos estacionales. En tercer lugar, aclara que desde tiempos coloniales venía produciéndose la llegada constante de personas desde Huixtán y Chamula, cuyos emplazamientos fueron reconocidos como ejidos en tiempos posrevolucionarios (Hotchkiss, 1959a: 6-7).

A pesar de ese flujo constante de población alteña hacia Teopisca, algo que resultaba evidente para John Hotchkiss era el dominio que los ladinos ejercían sobre los indígenas a mediados del siglo XX. Una muestra de ello era que el comité ejidal se encontraba subordinado al gobierno municipal (Hotchkiss, 1959a: 11). Otra evidencia era la ausencia del sistema de cargos civilreligiosos en los barrios. Al haber roto con su pueblo de origen, los indígenas migrantes debieron acomodarse al modo de organización implementado por los ladinos. Aun con todo lo anterior, la religiosidad observaba sus especificidades, como lo eran la práctica de un catolicismo popular en las colonias o la existencia de calendarios religiosos diferentes entre indígenas y ladinos (Hotchkiss, 1959a: 14-27).

John Hotchkiss nos ofreció un mundo agrícola variado para el caso de Teopisca. Los diferentes actores, los tipos de tenencia de la tierra, la particularidad de las prácticas agrícolas, las diversas formas de trabajo y la articulación con actividades no agrícolas son algunos de los aspectos que dan vida al retrato ofrecido (Hotchkiss, 1959a: 28-37).

Otro aspecto que en apariencia distinguía a Teopisca de pueblos vecinos, como Amatenango y Aguacatenango, era su organización social. Aunque aquí también los barrios resultaban ser aglutinantes de la vida social, estos no podían tomarse por unidades autónomas. Las migraciones constantes y la influencia de los ladinos hacían de los barrios indígenas espacios abiertos. En el caso de Teopisca era común la práctica de matrimonios entre indígenas residentes en distintos barrios. No obstante, cabe aclarar que era una rareza la celebración de nupcias entre indígenas y ladinos (Hotchkiss, 1959a: 37-41).

Pese a las múltiples articulaciones que John Hotchkiss halló entre unos y otros, lo que resultaba evidente en el caso de Teopisca era que para sus habitantes existían dos mundos, uno indígena y otro ladino. Así se desprende de las percepciones mutuas que ellos tenían: los ladinos consideraban que los “indios" de los barrios no hacían parte de la comunidad, además de que eran borrachos y pendencieros; a su vez, los indígenas creían que los ladinos siempre estaban buscando la forma de robarlos y engañarlos (Hotchkiss, 1959a: 44-46).

EntreDiversidades. Revista de Ciencias Sociales y Humanidades, vol. 8, núm. 1 (16), enero-junio 2021. Páginas: 186 - 211 ISSN-e: 2007-7610. https://doi.org/10.31644/ED.V8.N1.2021.A08 
Adicionalmente, John Hotchkiss preparó un pequeño documento donde cuestionó los estudios que hasta entonces se habían realizado sobre ladinización, por considerar que lanzaban generalizaciones a partir de trabajos de campo muy particulares. En lugar de ello, el antropólogo sugirió apuntar hacia una mayor claridad conceptual en la interpretación de dicho proceso (Hotchkiss, 1959b: 1).

A partir de su investigación en San Agustín Teopisca, John Hotchkiss señaló que algunos habitantes del pueblo no respondían al modelo ideal de indígena que se presentaba en otros lugares de Chiapas, peculiaridad que se desprendía del alto grado de integración que ellos tenían a la sociedad ladina local. Teniendo en cuenta que el lugar era un centro regional, los ladinos se distinguían por sus actividades como artesanos, negociantes e intermediarios comerciales, además de tener sus residencias en las calles principales de la localidad. Por su parte, las periferias del pueblo estaban pobladas por barrios de indígenas (Hotchkiss, 1959b: 2-3).

La calidad migrante de los indígenas que habitaban Teopisca a mediados del siglo XX no fue la única peculiaridad que John Hotchkiss identificó. Este grupo poblacional estaba integrado a la sociedad ladina por medio de instancias administrativas, lazos económicos y colaboración en fiestas religiosas (Hotchkiss, 1959b: 3).

John Hotchkiss concluyó que si bien los indígenas se encontraban subordinados a los ladinos, ellos contaban con mecanismos de participación política que les permitían actuar a favor de sí mismos. Adicionalmente, a pesar de la integración —o ladinización-, cada uno de los dos grupos identificaba al otro como diferente a través de un sistema de estereotipos que tenían que ver con aspectos tales como el lugar habitado, la lengua hablada o el vestido empleado (Hotchkiss, 1959b: 3-4).

\section{Venustiano Carranza}

Christopher Day identificó las desigualdades, conflictos y transformaciones presentes en Venustiano Carranza — antes San Bartolomé de Los Llanos-. Una de las principales características del pueblo en esos ańos eran las discrepancias entre los indígenas que vivían en las colonias de tierras bajas y aquellos que residían en la cabecera, pues estos últimos ya no consideraban a los primeros como parte de la comunidad; ni qué decir de la férrea competencia entre ganaderos y agricultores por las tierras de mejor calidad (Day, 1959: 1-3).

En otro trabajo, Arthur Rubel resaltó que desde finales del siglo XVIII San Bartolomé ya se trataba de un pueblo heterogéneo, donde existía una clara división entre indígenas y ladinos, distinguiéndose unos y otros por la lengua que hablaban — tzotzil y español, respectivamente- y el vestido que usaban (Rubel, 1959: 2-3).

Este antropólogo también se concentró en señalar los cambios que por aquellos años estaban ocurriendo en Venustiano Carranza. Como ya era un tópico común entre otros de sus colegas, Rubel también postuló que la carretera Panamericana había incrementado el comercio de ganado criado en los ranchos de los ladinos, lo que a su vez había generado conflictos con las tierras de los ejidatarios e indígenas (Rubel, 1959: 5-7).

Adicionalmente, y aunque persistía la rivalidad entre los cinco barrios de la cabecera municipal —Calvario, Convento, San Pedro Mártir, San Sebastián y Señor del Pozo-, la

EntreDiversidades. Revista de Ciencias Sociales y Humanidades, vol. 8, núm. 1 (16), enero-junio 2021. Páginas: 186 - 211 ISSN-e: 2007-7610. https://doi.org/10.31644/ED.V8.N1.2021.A08 
autoridad tradicional, encarnada por la jerarquía socio-religiosa, estaba siendo cuestionada por una camada de jóvenes bilingües. Este no era un fenómeno reciente ya que, al parecer, la Revolución transformó la manera en que eran reclutados los líderes. Por ejemplo, el indígena Bartolo Chaal se convirtió en líder político del pueblo gracias a su bilingüismo y conocimiento de los códigos impulsados por las instituciones federales, habilidades que lo llevaron a encabezar la defensa de las tierras comunales frente a las autoridades estatales y, de ese modo, constituirse en el principal intermediario entre los asuntos locales y los nacionales (Rubel, 1959: 18-25).

Otro nuevo líder, en este caso ladino, fue el maestro federal de apellido Zamudio. Antes de la llegada de este personaje el ayuntamiento indígena y el ladino habían operado de manera separada. Según documentó el investigador, al maestro Zamudio se deberían la familiarización de los jóvenes indígenas con el mundo ladino, el cuestionamiento del trabajo comunal y del sistema de reclutamiento de líderes por parte del ayuntamiento indígena, además de la unificación de los campesinos e indígenas en torno a la explotación de tierras y su distribución por medio de una oficina de Bienes Comunales (Rubel, 1959: 25-28).

En su conjunto, todos estos cambios habrían conducido a la proliferación de líderes y otras formas de liderazgo. No solo sucedió que los principales quedaron restringidos al campo religioso, sino que el uso de la tierra dejó de ser controlado por la envidia, la brujería y los naguales. El que los nuevos líderes, intermediarios entre el gobierno municipal y los barrios indígenas, ahora pertenecieran a organizaciones más allá del ámbito local y tuvieran habilidad para negociar a otros niveles, a su vez, había facilitado la entrada de ladinos al grupo indígena (Rubel, 1959: 28-35).

\section{Villa Las Rosas}

En la imagen esquemática que John Hotchkiss ofreció de Villa Las Rosas, a mediados del siglo $\mathrm{XX}$, sobresale la ascendencia política y económica que habían alcanzado los ladinos, quienes sostenían fuertes relaciones sociales con la gente de Teopisca, lugar del cual al parecer provenía una buena parte de ellos. Otra de las características que el antropólogo identificó fue el origen variado de su población indígena. Una parte de ella correspondía a los descendientes de los tzeltales que se establecieron desde tiempos coloniales en el pueblo de Pinola. Otra parte significativa de la población procedía de diversos lugares, principalmente de Los Altos y la zona tojolabal (Hotchkiss, 1959c: 1-2).

Por aquel entonces la distribución de la población en el pueblo de Villa Las Rosas mostraba un centro predominantemente ladino, alrededor del cual estaban ubicados varios barrios indígenas. Si bien gran parte de los hombres y mujeres de los barrios aún vestían de manera particular y se dedicaban principalmente al cultivo de maíz y caña, muchos de ellos también trabajaban para los ranchos de los ladinos, además de ofrecer sus servicios en las temporadas de corte para el ingenio Pujiltic. Asimismo, mientras que aún persistía una organización civil y religiosa en cada uno de los cinco barrios, paralelamente eran comunes los matrimonios inter-barrios y los cambios de residencia a conveniencia de los interesados (Hotchkiss, 1959c: 3-6).

En pocas palabras, John Hotchkiss sugirió que, a pesar de la vigencia de muchas de las tradiciones, parecía existir una fuerte tendencia hacia la ladinización. Además, a diferencia de Venustiano Carranza, donde se habían preservado gran parte de las costumbres indígenas pese

EntreDiversidades. Revista de Ciencias Sociales y Humanidades, vol. 8, núm. 1 (16), enero-junio 2021. Páginas: 186 - 211 ISSN-e: 2007-7610. https://doi.org/10.31644/ED.V8.N1.2021.A08 
a un largo período de convivencia con los ladinos, en Villa Las Rosas un proceso reciente de interacción con este mismo tipo de población había conducido a un rápido abandono de las prácticas tradicionales (Hotchkiss, 1959c: 7).

\section{Algunas reflexiones finales}

Una de las principales limitaciones de la mayoría de las monografías elaboradas en el marco del proyecto Man in Nature (El hombre en la naturaleza) fue la poca profundidad histórica delos análisis, que en muchas ocasiones ofreció interpretaciones de corto plazo acerca de las transformaciones ocurridas, las cuales no iban más allá de las políticas del Instituto Nacional Indigenista, las escuelas rurales federales, la reforma agraria o la propia confrontación revolucionaria.

Una contradicción recurrente en este tipo de trabajos fue partir del supuesto de que el objeto de estudio eran comunidades cerradas y, en el curso de la investigación, ofrecer innumerables testimonios de lo contrario. La tendencia a generalizar también apuntó que en estos pueblos existía un principio de nivelación social y económica, pese a que los celos por diferencias de estatus y riqueza estaban a la orden del día. Este tipo de suposiciones no dejaban de conducir hacia ciertos estereotipos de pobreza asociados a los pueblos indígenas, del mismo modo que en algunas ocasiones se reproducía una imagen idílica y estática que tendía a subvalorar los intercambios comerciales y las migraciones.

Con todo y las observaciones anteriores, una lectura detenida de las etnografías y trabajos relativos a temas específicos al interior de cada uno de los pueblos estudiados revela con claridad que los investigadores fueron más allá de los lineamientos bajo los cuales se planteó en un principio el proyecto. Las informaciones encontradas en campo condujeron a replantear muchas de las hipótesis iniciales, desarrollar metodologías novedosas, formular interpretaciones originales y abrir derroteros para las investigaciones futuras.

La tensión entre el molde de la comunidad corporada y la comprensión de los cambios y relaciones particulares estuvo presente en los trabajos que se ocuparon del pueblo de Aguacatenango. Elementos del modelo ideal coexistían con innovaciones en la construcción de las casas, el sistema de créditos y las actividades agrícolas. Adicionalmente, en este caso resultó evidente que las iniciativas impulsadas por el Instituto Nacional Indigenista fueron inoperantes.

En términos metodológicos, el trabajo relativo a los patrones de residencia en Aguacatenango resultó ser toda una novedad: en vez de ajustarse a las tipologías, se optó por estudiar las historias individuales, como también la movilidad física, económica y social de la pareja recién comprometida. Esta perspectiva de contraste entre el ideal y la práctica permitió acceder a la comprensión de aspectos sociales como las tensiones, desviaciones, marginaciones y áreas de refugio. Otra de las investigaciones mostró los mecanismos locales de resolución de conflictos, defensa de la autonomía política y resistencia a los gobiernos estatales y nacionales.

Algo muy similar a lo anterior se encontró en el caso de Amatenango del Valle. Los investigadores reportaron la resistencia a la presencia ladina, así como también atestiguaron los intercambios económicos, políticos, sanitarios, sociales y religiosos con pueblos y fincas de la región. En estos trabajos también son palpables las paradojas: en teoría, la tierra era comunal e

EntreDiversidades. Revista de Ciencias Sociales y Humanidades, vol. 8, núm. 1 (16), enero-junio 2021. Páginas: 186 - 211 ISSN-e: 2007-7610. https://doi.org/10.31644/ED.V8.N1.2021.A08 
inalienable, en la práctica, la compra y venta eran repetidas; se suponía la existencia de mecanismos de cohesión social y no obstante había numerosas muestras de relaciones centrífugas.

Pese a las contradicciones, son innegables los aportes en términos de la comprensión del papel cumplido por la brujería en la sanción de faltas y el control de las desigualdades económicas y sociales. Todavía más original fue el análisis del proceso que llevaba al asesinato de los brujos y la elaboración de una teoría local sobre la brujería.

El estudio de Amatenango del Valle condujo a comprender las complejidades de una economía de pequeńa escala. Los datos encontrados llevaron a cuestionar el uso de los modelos empresariales para analizar las economías pequeńas, pues, en lugar de perseguirse la máxima producción, en esta localidad se buscaba la equivalencia de riquezas a través de mecanismos de nivelación social.

El corto reporte sobre Chanal incorporó una perspectiva histórica más amplia. En este caso, se tuvo en cuenta la presencia y posterior expulsión de la población ladina e incluso el propio origen de la localidad a partir de una colonia desprendida de Oxchuc. Otro aspecto de gran relevancia fue el cambio de un patrón de asentamiento predominantemente disperso hacia uno de tipo nuclear. Se llegaron a reconocer las complejidades que albergaba el concepto de "pueblo vacío", pues si bien era una combinación de un centro y sus periferias, estas últimas iban desde secciones con diferentes pisos térmicos, pasando por colonias, hasta llegar a las fincas.

El pueblo de Huixtán, por su parte, fue identificado como un curioso caso de convivencia de hablantes de las lenguas tzeltal y tzotzil. Esta particularidad hizo necesario implementar un análisis que distinguiera las diferentes combinaciones que podían darse entre factores tales como el lugar de origen, la lengua, el vestido y la identidad. Otra especificidad de este pueblo era la presencia de un grupo considerable de ladinos, los cuales no solo residían en la cabecera sino también en las fincas, colonias y parajes de los alrededores. Si bien el patrón de asentamiento continuaba siendo mayoritariamente disperso, el tipo de residencia marcaba una tendencia hacia la neolocal, la organización política ahora consistía en una asamblea general y la propiedad de la tierra pasó de ser comunal a ejidal.

En Huixtán se encontraron diferencias en cuanto a calidad y cantidad de tierra distribuida entre las personas. De manera similar, fueron documentadas las actividades involucradas en la explotación de cultivos comerciales como el trigo y el café. También, se estudiaron las fiestas religiosas locales e intercambios mercantiles que las acompañaban. En lugar de apelar a diferentes raíces culturales, se optó por definir grupos socioculturales de acuerdo con características locales. Un último aporte fue la comprensión de la paradoja según la cual las personas menos "ladinizadas" eran quienes mejor recibían la ayuda del Instituto Nacional Indigenista.

En Oxchuc se encontró que el sistema de parentesco más común eran las familias nucleares, mientras que en el campo de la propiedad dominaba la venta de tierras. Por su parte, los hombres de prestigio habían ganado lugar a los grupos corporativos en el terreno de la autoridad, mientras que el trabajo estacional en las fincas era una forma común de obtener ingresos adicionales. La presidencia municipal pasó a ser ocupada por jóvenes bilingües. Se encontraron incontables conflictos entre las autoridades locales, regionales y nacionales. Por último, el sistema de autoridad

EntreDiversidades. Revista de Ciencias Sociales y Humanidades, vol. 8, núm. 1 (16), enero-junio 2021. Páginas: 186 - 211 ISSN-e: 2007-7610. https://doi.org/10.31644/ED.V8.N1.2021.A08 
de Oxchuc, antes basado principalmente en las sanciones de la brujería, fue socavado por la llegada de la religión protestante y la migración de los jóvenes hacia las fincas.

Una de las originalidades del reporte presentado para el caso de Teopisca es haber enseñado que la identidad indígena de algunos de sus habitantes respondía a la interacción entre personas y no a esencias preestablecidas. La investigación reveló la sucesión de innumerables migraciones de larga data. La jerarquía de cargos socio-religiosos brillaba por su ausencia. Asimismo, en el lugar se daba la confluencia de una gran diversidad de manifestaciones religiosas, como también resultaba evidente que el mundo agrícola era muy variado. Los barrios, en lugar de ser unidades autónomas, eran considerados espacios abiertos en los cuales había una intensa interacción entre ladinos e indígenas.

En vez de calcar generalizaciones para uno y otro pueblo, se apostó por estudiar casos concretos del proceso de cambio de identidad de indígenas a ladinos. En Teopisca la forma de ser indígena estaba definida por la articulación con la población ladina. Ambos grupos estaban integrados, a tal grado que confluían en esferas administrativas, económicas, sociales y festivas. Existía una indudable subordinación de los indígenas a los ladinos, pero también aparecieron diferentes mecanismos de resistencia.

En lo concerniente a Venustiano Carranza, destacaron los conflictos, transformaciones y desigualdades. Fueron reportados pleitos entre los propios indígenas, como también entre los ganaderos y los ejidatarios, respondiendo unos y otros a la lucha por la tierra. Se había producido un acercamiento entre algunos indígenas y ladinos pobres debido a que compartían condiciones de penuria económica. Esta transformación fue interpretada como el resultado de las políticas aplicadas por los gobiernos posrevolucionarios, las cuales habrían perseguido que la población fuera campesina, federal y ladina.

En Venustiano Carranza se encontró que el ejercicio de la autoridad pasó de un sistema de cargos conformado por ancianos a una generación de jóvenes bilingües que conocían los códigos políticos federales. Este proceso produjo multiplicidad de líderes y formas de liderazgo. En el pueblo había una camada de nuevos dirigentes caracterizados por su papel como intermediarios entre la comunidad local y el mundo externo.

Por último, se señalaron las claras conexiones entre los ladinos de Teopisca y Villa Las Rosas. En este último caso, el análisis se había alejado del modelo de la comunidad corporada, debido a la presencia de factores como el trabajo en las fincas. Había un aspecto que claramente distinguía a Teopisca de Villa Las Rosas: se trataba del acelerado y reciente proceso de ladinización que por aquellos tiempos estaba viviendo el último de los dos pueblos.

EntreDiversidades. Revista de Ciencias Sociales y Humanidades, vol. 8, núm. 1 (16), enero-junio 2021. Páginas: 186 - 211 ISSN-e: 2007-7610. https://doi.org/10.31644/ED.V8.N1.2021.A08 


\section{Bibliografía citada}

Barrera Aguilera, Óscar (2016). "El grano de la discordia: indios, ladinos y trigo en los Valles de Teopisca”, en Gonzalbo, Pilar y Mayer, Leticia (eds.). Conflicto, resistencia y negociación en la historia. México: El Colegio de México, pp. 337-373. También disponible en: https:// www.academia.edu/43001193/El grano de la discordia indios ladinos y trigo en los Valles de Teopisca

Barrera Aguilera, Óscar (2019a). "El hombre en la naturaleza: los resultados del Proyecto Chicago en Chiapas, 1956-1959”. LiminaR. Estudios Sociales y Humanisticos, XVII: 1 (ene.-jun.), pp. 97-113. También disponible en: http://liminar.cesmeca.mx/index.php/r1/article/ view/648

Barrera Aguilera, Óscar (2019b). Las Terrazas de Los Altos: lengua, tierra y población en la Depresión Central de Chiapas, 1775-1930. San Cristóbal de Las Casas, Chiapas, México: Centro de Investigaciones Multidisciplinarias sobre Chiapas y la Frontera SurUniversidad Nacional Autónoma de México / Consejo Estatal para las Culturas y las Artes del gobierno de Chiapas. También disponible en: http://www.libros.unam.mx/ las-terrazas-de-los-altos-lengua-tierra-y-poblacion-en-la-depresion-central-dechiapas-1775-1930-9786073027038-libro.html

Bohannan, Paul (1981). "Obituary: Eva Verbitsky Hunt, 1934-1980”. American Anthropologist, [en línea] 83 (4), Dic, pp. 892-894. Disponible en: https://doi.org/10.1525/ aa.1981.83.4.02a00090 (Consultado el 6 de noviembre de 2017).

Departments \& People (1980). “Departments \& People, September 1980". Anthropology News, 21 (3). Disponible en: https://anthrosource.onlinelibrary.wiley.com/ toc/15563502/1980/21/3 (Consultado el 6 de noviembre de 2017).

Encyclopedia.com (2017). Hunt, Eva (1934-1980). [en línea] Disponible en: https://www. encyclopedia.com/women/dictionaries-thesauruses-pictures-and-press-releases/hunteva-1934-1980 (Consultado el 6 de noviembre de 2017).

Eriksen, Annelin (2007). "Understanding Cultural Change: The Return of Core Anthropological Concepts". Reviews in Anthropology, 36 (2), pp. 131-154. Disponible en: https://doi. org/10.1080/00938150701344673 (Consultado el 1 de octubre de 2020).

Gacs, Ute, et al. (1988). Women Anthropologists: Selected Biographies. Chicago, United Sates: University of Illinois Press.

Guiteras Holmes, Calixta (1986 [1965]). Los peligros del alma. Visión del mundo de un tzotzil. 2a edición en espańol, Carlo Antonio Castro (trad.), con un Epílogo de Sol Tax. México: Fondo de Cultura Económica.

Letona Rodríguez, Paola Alejandra (2019). Antropología guatemalteca: una práctica heterodoxa $y$ heterogénea (1930-2013). Tesis para obtener el grado de Doctorado en Ciencias Antropológicas. División de Ciencias Sociales y Humanidades: Universidad Autónoma Metropolitana-Iztapalapa.

McQuown, Norman y Pitt-Rivers, Julian (comps.) (1970). Ensayos de antropología en la zona central de Chiapas. México: Instituto Nacional Indigenista, Secretaría de Educación Pública.

EntreDiversidades. Revista de Ciencias Sociales y Humanidades, vol. 8, núm. 1 (16), enero-junio 2021. Páginas: 186 - 211 ISSN-e: 2007-7610. https://doi.org/10.31644/ED.V8.N1.2021.A08 
Medina Hernández, Andrés (2015). “Antropología y geopolítica. La Universidad de Chicago en Los Altos de Chiapas: el proyecto Man-in-Nature (1956-1962)", en Medina Hernández, Andrés y Rutsch, Mechthild (coords.). Senderos de la antropología: discusiones mesoamericanistas y reflexiones históricas. México: Instituto Nacional de Antropología e Historia, Universidad Nacional Autónoma de México, pp. 205-274.

Pozas Arciniega, Ricardo (1948). Juan Pérez Jolote. Biografía de un tzotzil. México, D.F., México: Acta Antropológica.

Rodas Núñez, Isabel (2004). De españoles a ladinos. Cambio social y relaciones de parentesco en el Altiplano central colonial guatemalteco. Guatemala: Instituto Centroamericano de Prospectiva e Investigación (ICAPI).

Slocum, Marianna (1988). The Good Seed. Orange, California, United States: Promise Publishing Company.

Tax, Sol (1945). "Anthropology and Administration". América Indigena, V (1) ene., pp. 21-33.

Tax, Sol (1986 [1965]). "Epílogo. Cómo se escribió este libro”, en Guiteras, Calixta (autora). Los peligros del alma. Visión del mundo de un tzotzil. 2a edic. en español, Carlo Antonio Castro (trad.). México: Fondo de Cultura Económica, pp. 277-299.

De Vos, Jan (2010). "El tesoro de Teopisca o cómo nació y creció el pueblo ahora llamado Nicolás Ruiz”, en De Vos, Jan (autor). Camino del Mayab. Cinco incursiones en el pasado de Chiapas. México: Publicaciones de la Casa Chata, pp. 145-198.

Williams, Thomas Rhys (1966). "The Study of Change as a Concept in Cultural Anthropology". Theory Into Practice, 5 (1), feb., pp. 13-19.

\section{Documentos de archivo}

Calnek, Edward E. (1959). "Chanal", en Report on the "Man in Nature" Project (1956-1959), Pt. II, Microfilm Collection of Manuscripts on Cultural Anthropology, Joseph Regenstein Library, University of Chicago (MCA), Series XIV, No. 93, Chicago Universidad de Chicago, 20 pp.

Day, Christopher (1959). "Venustiano Carranza", en Report on the "Man in Nature" Project (1956-1959), Pt. II, Microfilm Collection of Manuscripts on Cultural Anthropology, Joseph Regenstein Library, University of Chicago (MCA), Series XIV, No. 93, Chicago, Universidad de Chicago, 19 pp.

Gearing, Fred, McC. Netting, Robert \& Lisa R. Peattie (eds.) (1960). Documentary History of the Fox Project 1948-1959. A Program In Action Anthropology. Directed by Sol Tax, Chicago, University of Chicago. Microfilm Collection of Manuscripts on Cultural Anthropology, Series LXXVI, No. 394, University of Chicago Library. Disponible en: https://www. lib.uchicago.edu/collex/collections/manuscripts-cultural-anthropology-1931-1992/ collection-manifest/

Hotchkiss, John (1959a). "Teopisca", en Report on the "Man in Nature" Project (1956-1959), Pt. II, MCA, Series XIV, No. 93, Chicago, Universidad de Chicago, 49 pp.

EntreDiversidades. Revista de Ciencias Sociales y Humanidades, vol. 8, núm. 1 (16), enero-junio 2021. Páginas: 186 - 211 ISSN-e: 2007-7610. https://doi.org/10.31644/ED.V8.N1.2021.A08 
Hotchkiss, John (1959b). "Markers of Acculturation in a Ladino-Indian Town”, en Report on the "Man in Nature" Project (1956-1959), Pt. III, Microfilm Collection of Manuscripts on Cultural Anthropology, Joseph Regenstein Library, University of Chicago (MCA), Series XIV, No. 94, Chicago, Universidad de Chicago, 7 pp.

Hotchkiss, John (1959c). "Villa Las Rosas", en Report on the "Man in Nature" Project (19561959), Pt. II, Microfilm Collection of Manuscripts on Cultural Anthropology, Joseph Regenstein Library, University of Chicago (MCA), Series XIV, No. 93, Chicago, Universidad de Chicago, 7 pp.

Metzger, Duane (1959). "A Preliminary Evaluation of Institutionalized Social Control and Its Contribution to Cultural Pluralism in the Highlands of Chiapas", en Report on the "Man in Nature" Project (1956-1959), Pt. III, Microfilm Collection of Manuscripts on Cultural Anthropology, Joseph Regenstein Library, University of Chicago (MCA), Series XIV, No. 94, Chicago, Universidad de Chicago, 21 pp.

Miller, Frank (1959a). "Preliminary Ethnographic Report on Huistán, Chiapas", en Report on the "Man in Nature" Project (1956-1959), Pt. III, Microfilm Collection of Manuscripts on Cultural Anthropology, Joseph Regenstein Library, University of Chicago (MCA), Series XIV, No. 94, Chicago, Universidad de Chicago, 33 pp.

Miller, Frank (1959b). "Social Structure and Changing Medical Practices in a Mexican Indian Community", en Report on the "Man in Nature" Project (1956-1959), Pt. III, Microfilm Collection of Manuscripts on Cultural Anthropology, Joseph Regenstein Library, University of Chicago (MCA), Series XIV, No. 94, Chicago, Universidad de Chicago, 7 pp.

Nash, June (1959a). "Amatenango del Valle", en Report on the "Man in Nature" Project (19561959), Pt. II, Microfilm Collection of Manuscripts on Cultural Anthropology, Joseph Regenstein Library, University of Chicago (MCA), Series XIV, No. 93, Chicago, Universidad de Chicago, 62 pp. + anexos.

Nash, June (1959b). "Social Structure and Social Organization in Oxchuc, Chiapas", en Report on the "Man in Nature" Project (1956-1959), Pt. III, Microfilm Collection of Manuscripts on Cultural Anthropology, Joseph Regenstein Library, University of Chicago (MCA), Series XIV, No. 94, Chicago, Universidad de Chicago, 25 pp. + anexos

Nash, Manning (1959a). "Witchcraft as Social Process in a Tzeltal Community", en Report on the "Man in Nature" Project (1956-1959), Pt. III, Microfilm Collection of Manuscripts on Cultural Anthropology, Joseph Regenstein Library, University of Chicago (MCA), Series XIV, No. 94, Chicago, Universidad de Chicago, 8 pp.

Nash, Manning (1959b). "The Small-Scale Economy: The Context of Economic Choice”, en Report on the "Man in Nature" Project (1956-1959), Pt. III, Microfilm Collection of Manuscripts on Cultural Anthropology, Joseph Regenstein Library, University of Chicago (MCA), Series XIV, No. 94, Chicago, Universidad de Chicago, 13 pp. + anexos.

EntreDiversidades. Revista de Ciencias Sociales y Humanidades, vol. 8, núm. 1 (16), enero-junio 2021. Páginas: 186 - 211 ISSN-e: 2007-7610. https://doi.org/10.31644/ED.V8.N1.2021.A08 
Report on the "Man in Nature" Project (1959). Report on the "Man in Nature" Project (19561959), 3 partes, June 30, 1959. Parte I (Microfilm Collection of Manuscripts on Cultural Anthropology, Joseph Regenstein Library, University of Chicago (MCA), Series XIV, No. 92); Parte II: (MCA, Series XIV, No. 93); Parte III: (MCA, Series XIV, No. 94), Chicago, Universidad de Chicago.

Rubel, Arthur (1959). "Changing Processes of Leadership Recruitment in Venustiano Carranza (San Bartolomé de Los Llanos), Chiapas", en Report on the "Man in Nature" Project (1956-1959), Pt. III, Microfilm Collection of Manuscripts on Cultural Anthropology, Joseph Regenstein Library, University of Chicago (MCA), Series XIV, No. 94, Chicago, Universidad de Chicago, 38 pp. + anexos.

Verbitsky, Muriel (1959a). "Aguacatenango", en Report on the "Man in Nature" Project (19561959), Pt. II, Microfilm Collection of Manuscripts on Cultural Anthropology, Joseph Regenstein Library, University of Chicago (MCA), Series XIV, No. 93, Chicago, Universidad de Chicago, 53 pp.

Verbitsky, Muriel (1959b). "Residence Patterns in a Tzeltal Community", en Report on the "Man in Nature" Project (1956-1959), Pt. III, Microfilm Collection of Manuscripts on Cultural Anthropology, Joseph Regenstein Library, University of Chicago (MCA), Series XIV, No. 94, Chicago, Universidad de Chicago, 50 pp.

EntreDiversidades. Revista de Ciencias Sociales y Humanidades, vol. 8, núm. 1 (16), enero-junio 2021. Páginas: 186 - 211 ISSN-e: 2007-7610. https://doi.org/10.31644/ED.V8.N1.2021.A08 